\title{
CXXXVIII. THE CHEMICAL CONSTITUTION OF SPERMINE.
}

\section{STRUCTURE AND SYNTHESIS.}

\author{
BY HAROLD WARD DUDLEY, OTTO ROSENHEIM \\ AND WALTER WILLIAM STARLING. \\ From the National Institute for Medical Research, Mt Vernon, \\ Hampstead, N.W. 3.
}

(Received August 2\%th, 1926.)

THE formula for spermine, isolated from animal organs and identical with the base occurring in human semen [Rosenheim, 1924], was established as $\mathrm{C}_{10} \mathrm{H}_{26} \mathrm{~N}_{4}$ by the work reported in the first of this series of communications [Dudley, M. C. Rosenheim and O. Rosenheim, 1924]. Carefully controlled oxidation of the base with hydrogen peroxide and with potassium permanganate failed to produce evidence of any resistant ring structure in the molecule; spermine does not reduce permanganate in faintly acid solution and displays no optical activity in the polarimeter. These observations and the hydrogen content justify the inference that it is a saturated aliphatic base which does not contain any asymmetric carbon atoms, assuming that no racemisation has occurred during its isolation.

The action of nitrous acid on spermine is complicated and in Van Slyke's apparatus yields indefinite results similar to those obtained with the aliphatic diamines. By the interaction of silver nitrite and spermine hydrochloride crystalline products are formed, but the reaction, on account of its complexity, was unlikely to throw direct light on the constitution of the base and was therefore not followed up: for the same reason the study of the action of magnesium on the chloroaurate was abandoned. It is of interest to note that the free base spermine, when pure, does not possess the characteristic odour with which it is usually associated, but that a volatile base with this property is produced both by the oxidation of the pure substance in all the above-mentioned reactions and also during the decomposition of the chloroaurate.

It has already been reported [Dudley and Rosenheim, 1925] that, on exhaustive methylation of spermine, ten methyl groups are taken up. This fact, together with the observation that spermine forms a tetrabenzoyl derivative, establishes the presence in its molecule of two NH-groups and two $\mathrm{NH}_{2}$-groups: the four nitrogen atoms are thus accounted for. 
The final clues to the constitution of the base were provided by an examination of the degradation products of the quaternary base, decamethylspermine, and of those resulting from destructive distillation of spermine hydrochloride. Among the products of the latter process pyrrolidine was identified and this suggested the presence in spermine of the chain $\mathrm{N}-\mathrm{C}-\mathrm{C}-\mathrm{C}-\mathrm{C}-\mathrm{N}$, since this same base is formed when the hydrochloride of tetramethylenediamine (putrescine) is destructively distilled.

Information concerning the remaining six carbon atoms was supplied by the degradation products obtained by distilling the sulphide of decamethylspermine. This salt was chosen in preference to the chloride since Clarke [1913] had found that by distilling the sulphide of the quaternary base

$$
\left(\mathrm{CH}_{3}\right)_{3} \cdot \mathrm{OH} \cdot \mathrm{N} \cdot\left[\mathrm{CH}_{2}\right]_{4} \cdot \mathrm{N} \cdot \mathrm{OH} \cdot\left(\mathrm{CH}_{3}\right)_{3}
$$

excellent yields of the corresponding tertiary base resulted, whilst Willstätter and Heubner [1907], using the chloride, obtained only trimethylamine and methylpyrrolidine.

It seemed therefore advisable, in view of the complexity of decamethylspermine and the probable presence in it of the $>\mathrm{N} \cdot\left[\mathrm{CH}_{2}\right]_{4} \cdot \mathrm{N}<$ group, to distil that salt which was less likely to give rise to ring compounds.

The main products obtained by the degradation of decamethylspermine sulphide were two basic fractions, one with a much higher boiling-point than the other. The more complex high-boiling base proved to be the tertiary base hexamethylspermine which of course was of no value in elucidating the structure of spermine; but from the lower-boiling basic fraction another tertiary base, tetramethyltrimethylenediamine $\left(\mathrm{CH}_{3}\right)_{2} \cdot \mathrm{N} \cdot\left[\mathrm{CH}_{2}\right]_{3} \cdot \mathrm{N} \cdot\left(\mathrm{CH}_{3}\right)_{2}$ was isolated and identified ${ }^{1}$. This suggested the presence in spermine of the chain $\mathrm{N}-\mathrm{C}-\mathrm{C}-\mathrm{C}-\mathrm{N}$.

The remaining six carbon atoms were therefore accounted for on the assumption that they consisted of two groups of three, each between two nitrogen atoms.

The two following formulae would, therefore, be in accordance with these analytical findings and all previously observed properties of spermine:

(a) $\mathrm{NH}_{2} \cdot \mathrm{CH}_{2} \cdot \mathrm{CH}_{2} \cdot \mathrm{CH}_{2} \cdot \mathrm{NH} \cdot \mathrm{CH}_{2} \cdot \mathrm{CH}_{2} \cdot \mathrm{CH}_{2} \cdot \mathrm{CH}_{2} \cdot \mathrm{NH} \cdot \mathrm{CH}_{2} \cdot \mathrm{CH}_{2} \cdot \mathrm{CH}_{2} \cdot \mathrm{NH}_{2}$;

(b) $\mathrm{NH}_{2} \cdot \mathrm{CH}_{2} \cdot \mathrm{CH}_{2} \cdot \mathrm{CH}_{2} \cdot \mathrm{CH}_{2} \cdot \mathrm{NH} \cdot \mathrm{CH}_{2} \cdot \mathrm{CH}_{2} \cdot \mathrm{CH}_{2} \cdot \mathrm{NH} \cdot \mathrm{CH}_{2} \cdot \mathrm{CH}_{2} \cdot \mathrm{CH}_{2} \cdot \mathrm{NH}_{2}$.

It was decided to test these two possibilities by synthesis.

The synthesis of $(a)$ was accomplished by condensing $\alpha . \delta$-diaminobutane (putrescine) with excess of $\alpha$-phenoxy $\gamma$-bromopropane. Treatment of the resulting compound, $\alpha \cdot \delta$-bis $\left[\gamma^{\prime}\right.$-phenoxypropylamino $]$-butane, with hydrobromic acid resulted in the replacement of the two phenoxy-groups by bromine and the action of ammonia on this dibromide gave the compound $(a)$.

\footnotetext{
1 Some of the data recorded on pp. 1088 and 1089 suggest that this fraction may also have contained a small amount of tetramethyltetramethylenediamine derived from the tetramethylenediamine moiety of the spermine molecule.
} 


\section{4 . H. W. DUDLEY, O. ROSENHEIM AND W. W. STARLING}

The synthesis is represented by the following reactions:

$$
\begin{aligned}
& \mathrm{NH}_{2} \cdot \mathrm{CH}_{2} \cdot \mathrm{CH}_{2} \cdot \mathrm{CH}_{2} \cdot \mathrm{CH}_{2} \cdot \mathrm{NH}_{2}+\mathrm{C}_{6} \mathrm{H}_{5} \mathrm{O} \cdot \mathrm{CH}_{2} \cdot \mathrm{CH}_{2} \cdot \mathrm{CH}_{2} \cdot \mathrm{Br} \text { (excess) } \\
& \text { (a. } \delta \text {-Diaminobutane) (a-Phenoxy- } \gamma \text {-bromopropane) } \\
& \longrightarrow \mathrm{C}_{6} \mathrm{H}_{5} \mathrm{O} \cdot \mathrm{CH}_{2} \cdot \mathrm{CH}_{2} \cdot \mathrm{CH}_{2} \cdot \mathrm{NH} \cdot \mathrm{CH}_{2} \cdot \mathrm{CH}_{2} \cdot \mathrm{CH}_{2} \cdot \mathrm{CH}_{2} \cdot \mathrm{NH} \cdot \mathrm{CH}_{2} \cdot \mathrm{CH}_{2} \cdot \mathrm{CH}_{2} \cdot \mathrm{OC}_{6} \mathrm{H}_{5} \\
& \stackrel{\mathrm{HBr}}{\longrightarrow} \mathrm{Br} \cdot \mathrm{CH}_{2} \cdot \mathrm{CH}_{2} \cdot \mathrm{CH}_{2} \cdot \mathrm{NH} \cdot \mathrm{CH}_{2} \cdot \mathrm{CH}_{2} \cdot \mathrm{CH}_{2} \cdot \mathrm{CH}_{2} \cdot \mathrm{NH} \cdot \mathrm{CH}_{2} \cdot \mathrm{CH}_{2} \cdot \mathrm{CH}_{2} \cdot \mathrm{Br} \\
& \text { (a. } \delta \text {-Bis }\left[\gamma^{\prime}\right. \text {-bromopropylamino]-butane) } \\
& \stackrel{\mathrm{NH}_{3}}{\longrightarrow} \mathrm{NH}_{2} \cdot \mathrm{CH}_{2} \cdot \mathrm{CH}_{2} \cdot \mathrm{CH}_{2} \cdot \mathrm{NH} \cdot \mathrm{CH}_{2} \cdot \mathrm{CH}_{2} \cdot \mathrm{CH}_{2} \cdot \mathrm{CH}_{2} \cdot \mathrm{NH} \cdot \mathrm{CH}_{2} \cdot \mathrm{CH}_{2} \cdot \mathrm{CH}_{2} \cdot \mathrm{NH}_{2} \\
& \text { (a. } \delta \text {-Bis[ } \gamma^{\prime} \text {-aminopropylamino]-butane) }
\end{aligned}
$$

This compound proved to be in all respects identical with spermine. It gave the characteristic insoluble phosphate, and comparison of this and other salts with the corresponding compounds prepared from spermine which had been isolated from animal organs revealed complete identity between the synthetic and the natural bases.

The constitution of spermine is therefore established as $\alpha . \delta$-bis $\left[\gamma^{\prime}\right.$-aminopropylamino]-butane.

\section{EXPERIMENTAL.}

\section{DestruCtive Distillation OF SPERMine HYDROCHLORIDE.}

The usual procedure for the separation of the reaction products was followed; namely, removal of ammonia as the chloroplatinate and subsequent conversion of the remaining bases into chloroaurates and picrates.

Evidence obtained in preliminary experiments suggested the presence of methylamine as well as of ammonia in the platinum fraction and of pyrrolidine and $N$-methylpyrrolidine in the gold fraction. Since the absence of $N$-methyl groups from spermine itself could be assumed from the negative result of an attempted determination by Hertzig and Meyer's method, the isolation of the methylated bases would obviously not contribute any additional information as to the constitutional formula. Only two experiments therefore are here reported, the first leading to the identification of ammonia and pyrrolidine and the second demonstrating the probable presence of $N$-methylpyrrolidine.

\section{(a) Identification of ammonia and pyrrolidine.}

$8 \mathrm{~g}$. spermine hydrochloride were heated, in quantities of 0.5 to $1 \mathrm{~g}$., in small sublimation tubes to $310^{\circ}$, at which temperature a cloud of subliming crystalline material was observed. The temperature of the bath was raised to $330^{\circ}$ and held there for 20 minutes when the decomposition was apparently complete. The sublimate consisted of white crystals mixed with purplish brown, oily liquid. Some charred material remained behind which was much less in amount if the reaction was carried out in a current of $\mathrm{CO}_{2}{ }^{1} .4 .5 \mathrm{~g}$. of the spermine hydrochloride were decomposed by this modified method, the remainder by simple heating.

1 It was found later that charring was almost completely avoided when the operation was conducted in vacuo. 
The contents of the tubes were dissolved in dilute $\mathrm{HCl}$, filtered, made alkaline and steam-distilled. The cloudy distillate, containing a small quantity of an oil, was rendered faintly acid by addition of $\mathrm{HCl}$. The oil dissolved and the clear solution was concentrated to about $120 \mathrm{cc}$. when the addition of $8 \mathrm{~g}$. platinum chloride in $20 \mathrm{cc}$. water produced an immediate crystalline precipitate $(7 \cdot 74 \mathrm{~g}$.). Recrystallisation of this platinum salt from water yielded $5 \cdot 9$ g. ammonium chloroplatinate.

Analysis. $0 \cdot 2793 \mathrm{~g}$. gave $0 \cdot 1228 \mathrm{~g}$. Pt.

Pt: found $43.96 \%$; calc. for $\left(\mathrm{NH}_{4}\right)_{2} \mathrm{PtCl}_{6}, 43.91 \%$.

The solution from which the insoluble platinum salt had been removed was evaporated to about $50 \mathrm{cc}$. when the addition of $3 \mathrm{~g}$. platinum chloride dissolved in a little water produced a further crop of $2.5 \mathrm{~g}$. of insoluble platinum salt. After platinum had been removed from the filtrate by means of $\mathrm{H}_{2} \mathrm{~S}$ the solution was made alkaline and steam-distilled. Half of the distillate, which smelt strongly of pyrrolidine, was titrated with $N \mathrm{HCl}$, requiring $17 \cdot 3 \mathrm{cc}$. for neutralisation (the other half was worked up in a different manner), and then concentrated to small bulk. The precipitate produced by the addition of gold chloride weighed $1.45 \mathrm{~g}$. This was recrystallised from $1 \% \mathrm{HCl}$, yielding stout prismatic needles. After three recrystallisations the melting-point remained constant (199-205 ${ }^{\circ}$ with decomposition), $0.292 \mathrm{~g}$. being obtained. On analysis it was found to contain $47 \cdot 17 \% \mathrm{Au}$ : pyrrolidine chloroaurate (M.P. $205-6^{\circ}$ ), $47.94 \% \mathrm{Au}: N$-methylpyrrolidine chloroaurate (M.P. $218^{\circ}$ ), $46 \cdot 36 \%$ $\mathrm{Au}$.

Since the analysis suggested the presence of a small amount of $N$-methylpyrrolidine (?) the chloroaurate was converted into the chloroplatinate, which crystallised in needles on adding alcohol to its aqueous solution.

From water it crystallised in orange-red columns and from aqueous alcohol in needles (M.P. $208^{\circ}$ with decomposition). It was identified as pyrrolidine chloroplatinate.

Analysis. $0 \cdot 1174 \mathrm{~g}$. gave $0 \cdot 0413 \mathrm{~g}$. Pt.

Pt: found, $35 \cdot 18 \%$; calc. for pyrrolidine chloroplatinate, $35 \cdot 32 \%$; for methylpyrrolidine chloroplatinate, $33 \cdot 62 \%$.

(b) Attempted identification of N-methylpyrrolidine.

The properties of the corresponding salts of pyrrolidine and $N$-methylpyrrolidine are, as is to be expected, very similar, the only pair displaying marked difference in melting-points being the picrates:

pyrrolidine picrate, $112^{\circ} ; \mathrm{N}$-methylpyrrolidine picrate, $218^{\circ}$.

In the following experiment, therefore, an attempt was made to separate the two bases by recrystallisation of the picrates.

$0.52 \mathrm{~g}$. spermine hydrochloride was decomposed and steam-distilled as in $(a)$. The distillate, after neutralisation, was evaporated to $20 \mathrm{cc}$. and the pyrrolidine bases were precipitated by the addition of Dragendorff's reagent (potassium bismuth iodide solution). The precipitate was suspended in $8 \%$

Bioch. $\dot{x x}$ 


\section{H. W. DUDLEY, O. ROSENHEIM AND W. W. STARLING}

$\mathrm{NaOH}$ solution and steam-distilled. The distillate was neutralised with picric acid and evaporated to dryness. The dry residue was recrystallised from absolute alcohol, thin leaflets being obtained. After three recrystallisations the amount remaining sufficed only for a melting-point determination. It softened at $200^{\circ}$, melting to an oil at $208-214^{\circ}$.

It was, therefore, probably a still slightly impure specimen of $N$-methylpyrrolidine picrate.

\section{Degradation OF DECAMETH YLSPERMine SULPHIDE.}

$8 \mathrm{~g}$. spermine hydrochloride were methylated and the mercurichloride of the quaternary ammonium base was isolated as described in the second paper of this series [Dudley and Rosenheim, 1925]. The mercurichloride was suspended in $3 \mathrm{l}$. of hot water and decomposed with $\mathrm{H}_{2} \mathrm{~S}$. After evaporating the filtrate to small bulk it was treated with excess of silver oxide. After filtration the solution of the free base was saturated with $\mathrm{H}_{2} \mathrm{~S}$ and then concentrated in vacuo (water-bath at $45-50^{\circ}$ ). The solution of the sulphide was run into a small Claisen flask immersed in a bath at $130-135^{\circ}$. When the distillation of water had slackened, the temperature of the bath was raised to $150^{\circ}$. A watery basic distillate (fraction A) boiling at about $100^{\circ}$ was collected, the temperature of the bath being slowly raised to $180^{\circ}$. The residue in the flask was then distilled in vacuo. A small fraction boiling below $100^{\circ}$ was collected separately and the main high-boiling fraction (B) distilled between $100^{\circ}$ and $120^{\circ}$ at $15-20 \mathrm{~mm}$. pressure while the temperature of the bath was raised gradually to $220^{\circ}$.

\section{Identification of tetramethyltrimethylenediamine.}

Fraction A required $12 \mathrm{cc} .10 \% \mathrm{HCl}$ for neutralisation, and contained a small quantity of an oil which had a garlic-like odour. This was shaken out with ether after a slight excess of $\mathrm{HCl}$ had been added. The ethereal solution gave the heavy white precipitate, characteristic of alkyl sulphides, on addition of alcoholic $\mathrm{HgCl}_{2}$ solution.

From the solution of the hydrochloride, sodium picrate precipitated a picrate which, after recrystallisation from water, melted at $198-202^{\circ}$ (yellow oil), but was not quite homogeneous: yield $4.9 \mathrm{~g}$. It was converted into the hydrochloride, the solution of which was evaporated to dryness. A small quantity of this salt in alkaline solution was treated with benzenesulphonyl chloride and the original picrate was recovered after this treatment, proving that the base was tertiary as anticipated. Judged by the properties of the recovered picrate, the base appeared to have undergone a slight purification during this process, to which, accordingly, the main bulk of the hydrochloride was subjected. It was dissolved in $6 \% \mathrm{NaOH}$ and shaken with 4 cc. benzenesulphonyl chloride, and, after the latter had disappeared, the still alkaline liquid was steam-distilled. Picric acid was added to the distillate and $4 \cdot 4 \mathrm{~g}$. 
picrate were recovered which appeared to be quite homogeneous, crystallising in long flat needles; M.P. 202-204 (yellow oil).

The properties of the picrate, chloroaurate and chloroplatinate, together with the analyses of these salts, are tabulated below (Tables I and II).

The apparently low boiling-point of the tertiary base, the physical properties and analyses of its picrate and chloroaurate all suggested; on reference to the literature, its identity with ethyldimethylamine. A specimen of this base was therefore prepared by Eschweiler's method [1905] and the assumption disproved by mixed melting-point determinations:

\begin{tabular}{|c|c|c|}
\hline & $\begin{array}{c}\text { Chloroaurates } \\
\text { M.P. } \\
216^{\circ} \text { (decomp.) }\end{array}$ & $\begin{array}{c}\text { Picrates } \\
\text { M.P. } \\
202-4^{\circ} \text { (to oi }\end{array}$ \\
\hline $\begin{array}{l}\text { thylamine } \\
\text { ple }\end{array}$ & $196-8^{\circ} \quad "$ & $\begin{array}{cc}202-4^{\circ} \\
170^{\circ} & \Rightarrow\end{array}$ \\
\hline
\end{tabular}

The molecular weight of the picrate was then determined by Rast's method [1923; see also Ssadikow and Winogradow, 1924].
(i) $5 \mathrm{mg}$. picrate dissolved in $100 \mathrm{mg}$. camphor
$\Delta \quad$ M.w.
(ii)
$50 \mathrm{mg}$.
3.3 606
$6.5 \quad 615$
Calculated for $\mathrm{C}_{8} \mathrm{H}_{20} " \mathrm{~N}_{2}\left(\mathrm{C}_{6} \mathrm{H}_{3} \mathrm{O}_{7} \mathrm{~N}_{8}\right)_{2} \quad " \quad \ldots . \quad-602$

This finding made it clear that the tertiary base had a molecular weight approximately twice that of ethyldimethylamine and, therefore, contained two tertiary nitrogen atoms. Since the $>\mathrm{N}$. $\left[\mathrm{CH}_{2}\right]_{4} . \mathrm{N}<$ group had already been detected in spermine it was at first thought that the tertiary base might be tetramethyltetramethylenediamine. The fact that the fraction containing the tertiary base had been collected at $100^{\circ}$, whilst tetramethyltetramethylenediamine boils at $169^{\circ}$ was easily explainable because water was present during this stage of the degradation and fraction $A$ was in effect a steam-distillate.

Comparison of the data recorded for this base by Willstätter and Heubner [1907] with those found for the tertiary base revealed similarity between the picrates and chloroaurates but disagreement in the case of the chloroplatinates. The tertiary base was therefore methylated in the usual way and compared directly with the quaternary ammonium salt prepared by exhaustive methylation of a gram of synthetic putrescine hydrochloride [Dudley and Thorpe, 1925] which was immediately available. Again discrepancies were encountered which excluded the identity of the tertiary base with tetramethyltetramethylenediamine. The small amount of synthetic putrescine in hand precluded the direct comparison of the two tertiary bases themselves.

The analyses of the various salts of the tertiary base from decamethylspermine and its quaternary ammonium derivative are consistently rather high for tetramethyltetramethylenediamine and agree well with those required for the corresponding derivatives of tetramethyltrimethylenediamine.

The latter base was therefore synthesised according to the directions of Clarke [1913], and a portion was methylated.

Direct comparison then proved conclusively the identity of the tertiary base from decamethylspermine with tetramethyltrimethylenediamine. 
The evidence is collected in the following three tables.

Table I. Analyses.

Picrate:

Salt analysed

(0.0809 g. gave 0.1484 g. nitron picrate)

Chloroaurate:

(0.1575 g. gave 0.0757 g. Au)

$(0 \cdot 2162 \mathrm{~g}$. gave $0 \cdot 1046 \mathrm{~g}$. Au)

Chloroplatinate:

$(0 \cdot 2253 \mathrm{~g}$. gave $0 \cdot 0805 \mathrm{~g}$. $\mathrm{Pt})$

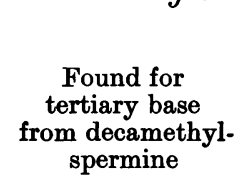

$\mathbf{7 7 \cdot 6 5}$

48.07)

$48 \cdot 38$

$35 \cdot 73$

Quaternary ammonium bases

Chloroaurate:

$(0 \cdot 1681$ g. gave 0.0780 g. Au)

Chloroplatinate:

$\left(0 \cdot 1917\right.$ g. lost 0.0056 g. $\mathrm{H}_{2} \mathrm{O}$ at $\left.103^{\circ}\right)$

$(0 \cdot 1861 \mathrm{~g}$. (dry) gave $0 \cdot 0638 \mathrm{~g} . \mathrm{Pt})$
$46 \cdot 40$

$2 \cdot 92$

$34 \cdot 29$

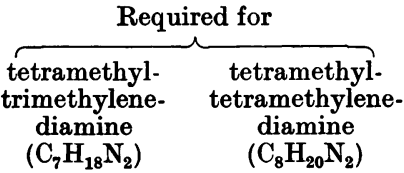

$77 \cdot 90$

$76.09 \%$

$48 \cdot 65$

$47 \cdot 82 \%$

$36 \cdot 11$

$35 \cdot 20 \%$

$46 \cdot 25 \%$

$47 \cdot 02$

Contains no $\mathrm{H}_{2} \mathrm{O}$

$33.51 \%$

Table II. Comparison of tertiary bases.

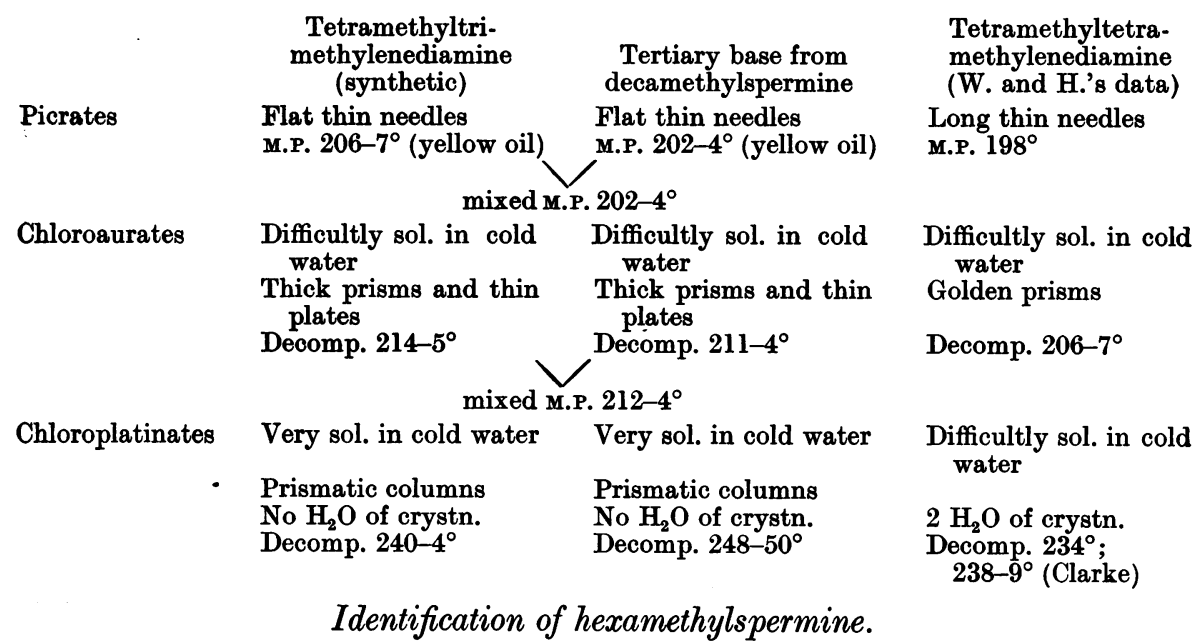

On addition of water to fraction B a small quantity of oil with a strong garlic-like odour separated and was removed by shaking with ether after the solution, which required $6.5 \mathrm{cc} .10 \% \mathrm{HCl}$ for neutralisation, had been made slightly acid to Congo red. After boiling the solution with charcoal and filtering, excess of $20 \%$ gold chloride solution was added. The chloroaurate obtained was recrystallised from $2.5 \% \mathrm{HCl}$; a smell of chlorine (?) was noticed and there was deposition of a small amount of metallic gold. The salt crystallised in balls of minute needles. Yield $5 \cdot 6 \mathrm{~g}$. Recrystallisation of this salt failing to give a pure compound (unsaturated substances were present), it was dis- 
Table III. Comparison of quaternary ammonium bases.

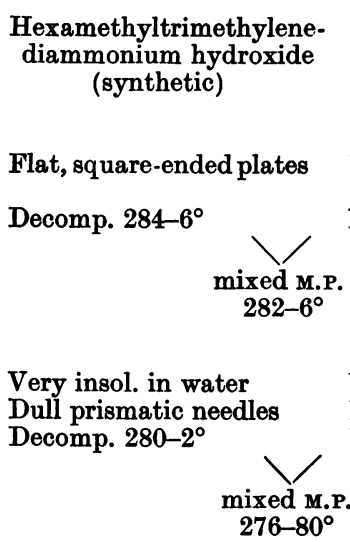

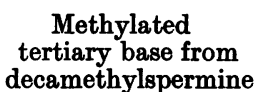

decamethylspermine

Picrates

Flat, square-ended plates

Decomp. 282-6 ${ }^{\circ}$
Hexamethyltetramethylenediammonium hydroxide

$\overbrace{\text { (Synthetic) (W. and H.'s data) }}$

Long, flat plates

Not decompd. at $294^{\circ}$

mixed M.P.

$282-6^{\circ}$

Chloroaurates

Very insol. in water

Dull prismatic needles

Decomp. 286-8 ${ }^{\circ}$
Aggregates of prismatic needles

Decomp. $285^{\circ}$

\section{mixed M.P.}

294-8 ${ }^{\circ}$

Chloroplatinates

Thin lustrous plates* (orange-yellow prismatic needles)

Not sol. in 7 parts boiling water

$1 \mathrm{H}_{2} \mathrm{O}$ of crystn.

Decomp. 282-6 ${ }^{\circ}$

\section{Orange-yellow* prisma-} tic needles

Not sol. in 7 parts boiling water

$1 \mathrm{H}_{2} \mathrm{O}$ of crystn.

Decomp. 280-4
Veryinsol.in water

Short thick prisms
Decomp. 300-2

Ora prismatic needles

Orange-yellow prismatic needles

Very insol. in water Aggregates of prisms Decomp. 304-9 ${ }^{\circ}$
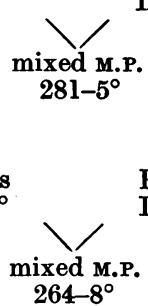

Mercurichlorides

Prismatic needles Decomp. 268-70
Prismatic needles

Decomp. 266-70 ${ }^{\circ}$

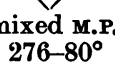

Sol. in 7 parts boil- Sol. in 7 parts boil. ing water

No $\mathrm{H}_{2} \mathrm{O}$ of crystn. Decomp. $284-6^{\circ}$

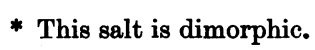

* This salt is dimorphic.

Prismatic needles

Decomp. 266-70

solved in dilute $\mathrm{HCl}$ and decomposed by means of $\mathrm{H}_{2} \mathrm{~S}$. The slightly hygroscopic hydrochloride obtained was dissolved in a small amount of water, alcohol was added until a permanent turbidity was produced and the solution on standing at $2^{\circ}$ for 2 days deposited crystals. These were dissolved in boiling methyl alcohol, the solution was filtered and ether was added until a faint turbidity was produced. After standing at $2^{\circ}$ the crystalline hydrochloride, no longer hygroscopic, was filtered off, 0.44 g. being obtained: M.P. (with decomposition), $273-276^{\circ}$.

Analysis. $0 \cdot 1146 \mathrm{~g}$. (dried at $100^{\circ}$ ) gave $0 \cdot 1868 \mathrm{~g}$. $\mathrm{CO}_{2}$ and $0 \cdot 0943 \mathrm{~g} \cdot \mathrm{H}_{2} \mathrm{O}$. $0 \cdot 1310 \mathrm{~g}$. (dried at $100^{\circ}$ ) gave $0 \cdot 1723 \mathrm{~g}$. $\mathrm{AgCl}$.

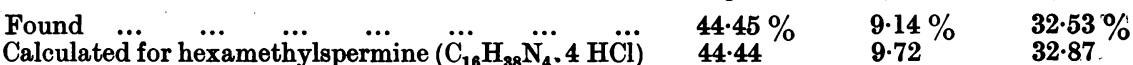

From the pure hydrochloride the chloroaurate was prepared. It was recrystallised from $5 \% \mathrm{HCl}$ yielding pale yellow rosettes of needles, M.P. (decomposition) $200-203^{\circ}$, which contained no water of crystallisation. 


\section{H. W. DUDLEY, O. ROSENHEIM AND W. W. STARLING}

Analysis. $0 \cdot 1782 \mathrm{~g}$. gave $0 \cdot 0850 \mathrm{~g}$. Au.

Au: found, $47 \cdot 70 \%$; calc. for $\mathrm{C}_{18} \mathrm{H}_{38} \mathrm{~N}_{4} .4 \mathrm{HAuCl}_{4}, 47 \cdot 88 \%$.

The identification was clinched by methylating the remainder of the hydrochloride in the usual manner and comparing the resulting quaternary ammonium base with that from spermine (decamethylspermine).

The picrate and chloroaurate were prepared and melted identically with the corresponding salts of decamethylspermine [Dudley and Rosenheim, 1925], mixed melting-point determinations showing no depression.

Analyses. $0 \cdot 0872 \mathrm{~g}$. picrate gave $0 \cdot 1505 \mathrm{~g}$. nitron picrate.

0.1755 g. chloroaurate gave $0.0810 \mathrm{~g}$. Au.

\begin{tabular}{|c|c|}
\hline & Picric acid \\
\hline 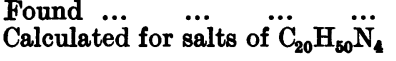 & $\begin{array}{l}73 \cdot 05 \% \\
72 \cdot 82\end{array}$ \\
\hline
\end{tabular}

III. OXIDATION OF, AND ACTION OF NITROUS ACID ON SPERMINE.

Oxidation. Spermine is readily oxidised by a variety of reagents, but since the study of the products formed did not contribute directly to the elucidation of the structure of the base, the experiments will not be described in detail. Vigorous oxidation with $\mathrm{KMnO}_{4}$ and with $\mathrm{H}_{2} \mathrm{O}_{2}$ yielded a small quantity of an acid, probably succinic, derived doubtless from the tetramethylene group in spermine.

Milder oxidation gives a volatile base with which the characteristic odour of semen is associated. This substance is constantly formed under conditions in which oxidative reactions may occur. If, for instance, an aqueous suspension of spermine chloroaurate is heated on the water-bath a copious precipitate of metallic gold is produced while the spermine is simultaneously partially oxidised; the action of magnesium on spermine chloroaurate, described by Schreiner [1878] involves, in all probability, a similar oxidation. Further, when a solution of spermine is warmed with silver oxide, the volatile base is produced and at the same time metallic silver is deposited as a mirror. Since this mirror is not produced in the presence of "dimedon" it is possible that one of the first substances formed in the reaction is an aldehyde.

The base is volatile in steam and forms a crystalline, readily oxidisable hydrochloride and a chloroaurate (M.P. 204-206 (with decomposition): $\mathrm{Au}=48.45 \%$ ). Apparently Wrede [1926] obtained the same base from the products formed by oxidising spermine with metallic copper and air, but did not succeed in identifying it.

In the light of the now established constitution of spermine it is suggested that the new base may have the structure of a $N-\gamma$-aminopropylpyrroline. The data so far recorded by Wrede are in agreement with this assumption which can easily be tested by synthesis.

Action of nitrous acid. The volatile base mentioned above is also formed by the action of $\mathrm{HNO}_{2}$ on spermine, together with a substance giving a nitrosoreaction. In view of the complexity of the reaction it is not surprising that 
Van Slyke determinations give inconclusive results. Varying proportions of gas, measured as nitrogen, are evolved according to the length of time the reaction is allowed to proceed. In a series of determinations quantities of gas were measured corresponding to $65 \%$ of the total $\mathrm{N}$ after 30 minutes, $76 \%$ after 1 hour and $85 \%$ after 2 hours. Wrede [1926] obtained $83 \%$ of the theoretical quantity after 1 hour under the conditions of his experiments and assumed from this result that spermine contains three $\mathrm{NH}_{2}$-groups and, since it forms tetraacyl derivatives, one $\mathrm{NH}$-group. These assumptions are disproved by the combined results of methylation and benzoylation reported in the previous papers of this series and by the synthesis described in the present communication.

\section{SYNTHESIS OF SPERMINE}

\section{$\alpha . \delta$-Bis $\left[\gamma^{\prime}\right.$-phenoxypropylamino]-butane hydrobromide.}

$6 \cdot 3 \mathrm{~g}$. tetramethylenediamine ${ }^{1}$, distilled over sodium, and 60 g. $\alpha$-phenoxy$\gamma$-bromo-propane, prepared according to v. Braun and Beschke's directions [1906], were dissolved in $180 \mathrm{cc}$. absolute alcohol and heated on a water-bath under a reflux condenser. Within 25 minutes crystalline material began to separate and after 4 hours' heating this was filtered off, $16 \cdot 1 \mathrm{~g}$. being obtained. This consisted of a mixture of the desired diphenoxy-compound together with some $\alpha$ - $\left(\gamma^{\prime}\right.$-phenoxypropylamino $)-\delta$-amino-butane hydrobromide, which was found also in considerable quantity in the alcoholic filtrate.

On recrystallisation from $260 \mathrm{cc}$. water the diphenoxy-compound was obtained in a pure condition; yield $9 \cdot 2 \mathrm{~g}$.; long thin plates, M.P. $292^{\circ}$ (dark-red liquid).

Analysis. $0 \cdot 1042 \mathrm{~g}$. gave $0 \cdot 0750 \mathrm{~g}$. $\mathrm{AgBr}$.

$\mathrm{Br}$ : found, $30.64 \%$; calc. for $\mathrm{C}_{22} \mathrm{H}_{34} \mathrm{O}_{2} \mathrm{~N}_{2} \mathrm{Br}_{2} ; 30.88 \%$.

From this hydrobromide the picrate was prepared, crystallising from $90 \%$ alcohol in needles, M.P. $178-180^{\circ}$ (brown oil).

\section{$\alpha . \delta$-Bis[ $\gamma^{\prime}$-bromopropylamino]-butane hydrobromide.}

$5 \mathrm{~g}$. of the above phenoxy-compound were heated in a sealed tube with 25 cc. $\mathrm{HBr}$ solution (Sp.G. 1.7) at $100^{\circ}$ for 18 hours.

On shaking the contents of the tube with ether to remove the phenol formed in the reaction, a crystalline substance separated from the aqueous layer (yield 4.55 g.). After recrystallisation from $250 \mathrm{cc} .96 \%$ alcohol 3.24 g. were obtained.

The substance, which was found to be the desired dibromo-compound, forms glistening broad plates and melts with effervescence at $274^{\circ}$.

1 The putrescine hydrochloride used in this synthesis was prepared by Dr J. Marshall, of Boots' Pure Drug Co., Nottingham, who very kindly presented us with a very pure specimen of this salt, enabling us to carry out the synthesis on a small scale. For this and the larger quantities with which he has subsequently supplied us, we wish to tender our best thanks. 


\section{H. W. DUDLEY, O. ROSENHEIM AND W. W. STARLING}

Analysis. $0 \cdot 1074 \mathrm{~g}$. gave 0.1646 g. $\mathrm{AgBr}$.

$\mathrm{Br}$ : found, $65.21 \%$; calc. for $\mathrm{C}_{10} \mathrm{H}_{24} \mathrm{~N}_{2} \mathrm{Br}_{4}, 65.03 \%$.

From the hydrobromide the picrate was prepared. After recrystallisation from $96 \%$ alcohol it was obtained as prismatic crystals, M.P. $186-188^{\circ}$ (brown oil).

\section{$\alpha . \delta$-Bis $\left[\gamma^{\prime}\right.$-aminopropylamino]-butane phosphate. \\ (Synthetic spermine phosphate.)}

4.55 g. of the above bromo-compound were heated in 1-2 g. lots with approximately 20 volumes of alcoholic ammonia (15-20\% by weight) in sealed tubes at $100^{\circ}$ for 7 hours. The alcohol and excess of ammonia were then removed by distillation in vacuo, leaving a white crystalline residue ${ }^{1}$. This was dissolved in water and solid $\mathrm{NaOH}$ was added to give a $50 \%$ solution which was then steam-distilled. From the distillate $(1500 \mathrm{cc}$ ) $1 \cdot 3 \mathrm{~g}$. insoluble phosphate was obtained by the method already described for the isolation of natural spermine phosphate [Dudley, M. C. Rosenheim and O. Rosenheim, 1924]. For analysis it was recrystallised from water and the picrate, picrolonate, chloroaurate, chloroplatinate and benzoyl-derivative were prepared from it. Comparison of these salts with those of spermine isolated from animal organs revealed complete identity, as judged by crystalline form, melting-points and mixed melting-point determinations.

\section{Analyses.}

Phosphate. 0.1825 g. lost 0.0396 g. $\mathrm{H}_{2} \mathrm{O}$ at $105^{\circ}$.

$\mathrm{H}_{2} \mathrm{O}$ found; $21 \cdot 69 \%$.

Calc. for $\mathrm{C}_{10} \mathrm{H}_{26} \mathrm{~N}_{4} \cdot 2 \mathrm{H}_{3} \mathrm{PO}_{4}, 6 \mathrm{H}_{2} \mathrm{O}: \mathrm{H}_{2} \mathrm{O}, 21 \cdot 34 \%$.

$0 \cdot 1429$ g. dry salt gave $\mathrm{NH}_{3}(\mathrm{Kjeldahl})=14 \cdot 39$ cc. $\mathrm{N} / 10 \mathrm{H}_{2} \mathrm{SO}_{4}$.

0.2117 g. dry salt gave 0.1180 g. $\mathrm{Mg}_{2} \mathrm{P}_{2} \mathrm{O}_{7}$.

Found: $\mathrm{N}, 14 \cdot 10 \%$;, $15 \cdot 53 \%$.

Calc. for $\mathrm{C}_{10} \mathrm{H}_{26} \mathrm{~N}_{4} .2 \mathrm{H}_{3} \mathrm{PO}_{4}: \mathrm{N}, 14 \cdot 07 \% ; \mathrm{P}, 15.56 \%$.

Picrate. 0.0497 g. gave 0.0962 g. nitron picrate.

Found: picric acid, $81.92 \%$.

Calc. for $\mathrm{C}_{10} \mathrm{H}_{26} \mathrm{~N}_{4} \cdot 4 \mathrm{C}_{6} \mathrm{H}_{3} \mathrm{O}_{7} \mathrm{~N}_{3}$ : picric acid, $81.98 \%$.

Chloroplatinate. $0 \cdot 1931 \mathrm{~g}$. lost $0 \cdot 0134 \mathrm{~g}$. at $105^{\circ}$ and the dry salt gave $0.0688 \mathrm{~g}$. Pt.

Found: $\mathrm{Pt}, 38 \cdot 28 \%$.

Calc. for $\mathrm{C}_{10} \mathrm{H}_{26} \mathrm{~N}_{4} \cdot 2 \mathrm{H}_{2} \mathrm{PtCl}_{6}$ : $\mathrm{Pt}, 38 \cdot 17 \%$.

The proof of the structure of spermine afforded by this investigation raises several points of biochemical interest. This is the first instance of a base of the type $\mathrm{NH}_{2} \cdot \mathbf{R} . \mathrm{NH} \cdot \mathrm{R}^{\prime}$.NH.R. $\mathrm{NH}_{2}$ being found in nature. It is possible

\footnotetext{
${ }^{1}$ Spermine phosphate can be precipitated directly from an aqueous solution of this residue by means of ammonium phosphate, but it is contaminated with insoluble phosphates of secondary reaction products which are difficult to separate by recrystallisation.
} 
that future work may disclose the presence of similar compounds in living tissues, and furnish a clue to the origin and function of this interesting base ${ }^{1}$.

The soluble phosphate, already reported as accompanying spermine in the processes of isolation from animal tissues [Dudley, M. C. Rosenheim and 0 . Rosenheim, 1924] may prove to be a salt of a base of this type and the question is now receiving attention.

In connection with the extraordinary insolubility of spermine phosphate it is interesting to note that a base of similar structure, namely "triethylenetetramine" $2 \mathrm{NH}_{2}\left[\mathrm{CH}_{2}\right]_{2} \cdot \mathrm{NH}$. $\left[\mathrm{CH}_{2}\right]_{2} \cdot \mathrm{NH}$. $\left[\mathrm{CH}_{2}\right]_{2} \cdot \mathrm{NH}_{2}$ does not form an unusually insoluble phosphate.

The presence in spermine of the trimethylenediamino-group is of considerable interest. The occurrence of trimethylenediamine, or its derivatives, in nature has not hitherto been established, although it has been reported.

Brieger [1887] isolated from cultures of $V$. cholerae, besides putrescine and cadaverine, a base whose elementary composition agreed with that of trimethylenediamine, but the substance has never been re-investigated.

Njegovan [1912], working on bases from plant phosphatides, obtained a gold salt which he considered might be that of completely methylated trimethylenediamine. The evidence, however, is not in the least convincing and has, indeed, been vigorously challenged by Trier [1912].

In spermine we have, indisputably, a derivative of trimethylenediamine, a fact which renders it more probable that the base itself may be encountered among the products of biological activity.

\section{Summary.}

1. Methylation and benzoylation of spermine proved that the base contains two $\mathrm{NH}_{2}$-groups and two $\mathrm{NH}$-groups.

2. The presence of the chains $\mathrm{N}-\mathrm{C}-\mathrm{C}-\mathrm{C}-\mathrm{C}-\mathrm{N}$ and $\mathrm{N}-\mathrm{C}-\mathrm{C}-\mathrm{C}-\mathrm{N}$ was inferred from the identification of pyrrolidine among the products of destructive distillation of spermine hydrochloride, and of tetramethyltrimethylenediamine obtained by the degradation of decamethylspermine.

3. The following structural formula for spermine, based on these observations, was proved to be correct by synthesis:

$\mathrm{NH}_{2} \cdot \mathrm{CH}_{2} \cdot \mathrm{CH}_{2} \cdot \mathrm{CH}_{2} \cdot \mathrm{NH} \cdot \mathrm{CH}_{2} \cdot \mathrm{CH}_{2} \cdot \mathrm{CH}_{2} \cdot \mathrm{CH}_{2} \cdot \mathrm{NH} \cdot \mathrm{CH}_{2} \cdot \mathrm{CH}_{2} \cdot \mathrm{CH}_{2} \cdot \mathrm{NH}_{2}$ ( $\alpha . \delta$-bis $\left[\gamma^{\prime}\right.$-aminopropylamino]-butane).

1 The pharmacological action of spermine has been investigated by Prof. Gibbs in this Institute and the results will be published shortly.

${ }^{2}$ We are indebted to Dr T. A. Henry for a specimen of this base. 
1094 H. W. DUDLEY, O. ROSENHEIM AND W. W. STARLING

\section{REFERENCES.}

von Braun and Beschke (1906). Ber. deutsch. chem. Ges. 39, 4120.

Brieger (1887). Berlin. klin. Woch. 24, 817.

Clarke (1913). J. Chem. Soc. 103, 1689.

Dudley and Rosenheim (1925). Biochem. J. 19, 1032.

Dudley, Rosenheim, M.C. and Rosenheim, O. (1924). Biochem. J. 18, 1263.

Dudley and Thorpe (1925). Biochem. J. 19, 845.

Eschweiler (1905). Ber. deutsch. chem. Ges. 38, 881.

Njegovan (1912). Z. physiol. Chem. 76, 1.

Rast (1923). Z. physiol. Chem. 126, 111.

Rosenheim (1924). Biochem. J. 18, 1253.

Schreiner (1878). Liebig's Ann. 194, 68.

Ssadikow and Winogradow (1924). Biochem. Z. 150, 368.

Trier (1912). Utber einfache Pflanzenbasen, etc. (Berlin).

Willstätter and Heubner (1907). Ber. deutsch. chem. Ges. 40, 386.

Wrede (1926). Z. physiol. Chem. 153, 291. 